\title{
Neruda y la resistencia a los antibióticos
}

\author{
ALEJANDRO COTERA
}

\section{Neruda and antimicrobial resistance}

Antimicrobial resistance has been a problem in medicine, since their incorporation to clinical practice. Numerous papers have been written on the subject. The analysis of two poems by Pablo Neruda "How much does a man live" and "Larynx", included in the volume "Estravagario" and published for the first time in 1957 and 1958, give us an incredible revelation about the concept of resistance. In these poems aureomycin, the first antimicrobial of the family of tetracyclines, was included as a poetic figure and the therapeutic action of antimicrobials was described. "Never so much bugs died / tons of them fell / but the few that remained alive / manifested their perversity". These writings incorporated novel concepts, even for physicians of that time and described the closeness of death that a patient may perceive during the course of a given disease. The capacity of Pablo Neruda to extract the essence of situations and to anticipate to conditions that only years later became clinically relevant problems, is noteworthy.

(Rev Med Chile 2011; 139: 955-958).

Key words: Anti-bacterial agents; Drug resistance, microbial; Neruda; Poetry.
Departamento de Medicina, Hospital Clínico de la Universidad de Chile. Santiago de Chile.

Recibido el 22 de diciembre de 2009. El autor de este artículo, Profesor de Medicina de la Universidad de Chile, distinguido nefrólogo y miembro destacado de la Sociedad Médica de Santiago, falleció el 10 de junio 2010. Este artículo se publica como un homenaje póstumo a su memoria, agradeciendo la colaboración de su esposa, Dra. Myriam Alvo A.

\section{$Y$ aquel que en todas ciencias no florece $y$ en todas artes no es ejercitado el nombre de Poeta no merece.}

Clarinda, Discurso en loor de la poesía, 1608.

Por supuesto, no espera uno encontrar en la obra de Pablo Neruda alcances importantes a asuntos del área bio-médica. Pero nada escapa a la curiosidad infinita del Vate. Abordaré aquí un ejemplo sobrecogedor de su capacidad para extraer la esencia misma de un fenómeno biológico, apenas vislumbrado al momento de escribir Neruda un cierto poema pero, que con el tiempo, se ha transformado en un tema de la mayor relevancia en medicina: la resistencia a los antibióticos.

Tanto para el neófito como para el principiante es difícil extraer la esencia de los fenómenos de la naturaleza, aquello en que reside su belleza. El primero se extravía en los detalles que más llaman la atención a su mirada ignorante, aspectos que no necesariamente son el centro de su importancia, colateralidades que rápidamente dejarán de ser ciertas y que sólo llamaron su atención por no haberlas conocido antes. Al principiante, por su lado, el ímpetu juvenil, ansia de conocimiento y deseo de enciclopedismo lo desvían del camino impidiéndole llegar a la esencia y lo dejan en los tecnicismos difíciles de explicar.

En el campo médico, el entendimiento profundo requiere una perspectiva de largo plazo, un proceso de maduración activa, una lenta decantación. Sólo entonces surge lo importante y bello, la posibilidad de explicar lo difícil en palabras simples. Los grandes profesores no lo son tanto por sus complicados conocimientos técnicos, necesarios por cierto para llegar al resultado, sino por haber atravesado esos conocimientos hasta descubrir la belleza y la importancia del fenómeno científico.

Neruda parece recorrer un camino diferente, una vía rápida. Difícil imaginar que haya dedicado mucho tiempo al estudio del asunto aludido, a mayor razón si pensamos que el problema apenas se conocía y ni siquiera se sospechaba la importancia que llegaría a tener. Es como si hubiese tomado el problema al vuelo y acortado el camino a la esencia 
con un catalizador mezcla de genialidad e intuición, y además predice su futura importancia con unos pocos versos imposibles de creer. Y escritos, además, con su maestría habitual.

Me estoy refiriendo específicamente a un fragmento del poema "Y cuánto vive", incluido en el volumen Estravagario (Buenos Aires, Losada, 1958) y talvez asociado a otro poema del mismo libro, "Laringe", que fue escrito a raíz de una seria afección a las cuerdas vocales: «Valentín, ya sabes que el médico me ordena silencio por dos meses... Juvencio Valle hubiera estado feliz. Yo me alegré porque se pensaba algo peor. Tengo un librito en el que escribo mis pensamientos como ser: a qué hora comemos?» (carta a Volodia Teiteiboim, fechada en Isla Negra el 17.01.1958). El poema "Y cuánto vive" comienza justamente con una secuencia de 'pensamientos' (bajo forma de interrogantes) sobre la duración de la vida, vale decir, sobre la muerte ineluctable ( $\mathrm{y}$ no olvidemos que, al momento en que esos 'pensamientos' se escriben, la primera causa de muerte en el mundo son las enfermedades infecciosas):

Cuánto vive el hombre, por fin?
Vive mil días o uno solo?
Una semana o varios siglos?
Por cuánto tiempo muere el hombre?
Qué quiere decir "Para Siempre"?
Preocupado por este asunto
me dediqué a aclarar las cosas.

A través de estas preguntas el poeta replantea una cuestión fundamental para el hombre. Una circunstancia biográfica, un riesgo de enfermedad incurable, ha funcionado como detonante. La búsqueda de respuesta aparece diseñada como una interrogación sucesiva y ascendente a tres categorías (simbólicas) de expertos: a los sabios sacerdotes en el nivel metafísico, a los médicos en el nivel científico, a los enterradores en el nivel de la vitalidad cotidiana y popular. En esta ocasión, claro está, me interesa desmenuzar el notable fragmento de la interrogación a los médicos, que en estas materias se supone puedan tener opinión.

Los médicos me recibieron, entre una consulta y otra, con un bisturí en cada mano, saturados de aureomicina, más ocupados cada día.
Neruda primero describe el ambiente típicamente médico, entre una consulta y otra, más ocupados cada día. Es poco probable que él mismo haya sido atendido por los médicos con prisa, pues a la fecha era ya un hombre famoso y de muchos contactos, pero acierta al describir una actitud frecuente, por todos conocida, y que ha llegado a ser parte de la personalidad misma de los médicos. Talvez conoció esta situación en su infancia de niño enfermizo.

Acierta también al describir a los médicos provistos de su armamento terapéutico, «con un bisturí en cada mano», dispuestos a curarlo todo, incluso aquello que no tiene remedio. El furor curandi de un oficio que es más llevadero cuando el médico se concentra en sus grandes capacidades para aliviar al prójimo, olvidando su pequeñez ante la enfermedad.

Al paso, como parte de la ambientación hay un éter que lo envuelve densamente todo: saturados de aureomicina. Aureomicina, la desliza como que no quiere la cosa, pasa delante del lector como un bello neologismo. Pero no: la aureomicina es la clortetraciclina, el primer antibiótico de la familia de las tetraciclinas. Obtenido a partir del Sreptomyces aureofaciens, resultado de una búsqueda a nivel mundial de microorganismos del suelo productores de antibióticos. Fue introducido en el uso clínico en 1948 y su vida fue más bien corta al ser reemplazado por la oxitetraciclina, su derivado inmediato dos años más tarde.

En Chile su uso no fue muy amplio, sólo se encuentran dos referencias en la bibliografía nacional. En 1950, el Dr. Werner Bustamante reporta en la Revista Chilena de Pediatría su experiencia en dos casos de Coqueluche tratados con aureomicina. En aquellos tiempos el uso de un fármaco en Chile dos años después de su introducción a nivel mundial debe haber sido todo un acontecimiento, entre otros motivos por las limitaciones económicas. Así se deduce del reporte del Dr. Bustamante, quien al describir uno de sus casos señala: «En un comienzo recibe sedantes y vitamina $\mathrm{C}$, pero en vista de que los padres cuentan con las facilidades del caso para adquirir aureomicina, se suspende todo tratamiento y se le instituye, a los 12 días aproximadamente de enfermedad, un tratamiento con este nuevo antibiótico». Dos años más tarde el Dr. Julio Meneghello, uno de los padres de la pediatría en Chile, publica su experiencia con el uso de aureomicina oral en la meningitis aguda 
purulenta del niño. En este caso se trata de 16 niños con infección meníngea, en que en 9 el tratamiento con el nuevo antibiótico fue exitoso y en 7 fracasó, lo que sugiere que para entonces ya había surgido la resistencia de los gérmenes a la clortetraciclina, que como veremos es otra de las sorpresas que nos brinda el poema.

Quien haya mencionado a Neruda la existencia de tal antibiótico debe haber sido alguien muy bien informado o haber captado el valor del nombre aureomicina como material poético. Ya hemos visto que la vida del antibiótico fue más bien corta al ser reemplazado por otro derivado. Por Chile su paso fue fugaz, entre 1950 y 1952 (Estravagario comenzó a escribirse en 1957 y se publicó en 1958), todo en un plazo muy corto en relación a la velocidad con que la información fluía a mediados del siglo pasado. Si bien Neruda viajó mucho en esos años, es poco probable que en viajes llenos de actividades literarias y políticas se haya informado de la existencia del novel antibiótico.

Es posible que su fuente haya sido el Dr. Francisco Velasco, su amigo desde 1952, después vecino en "La Sebastiana” (casa de Neruda en Valparaíso) y consejero en asuntos médicos. El Dr. Velasco, fue director del Hospital Salvador de Valparaíso, un hospital dedicado a enfermos mentales, pero antes fue médico infectólogo. También es un hombre sensible, profesor de historia del arte, ha escrito varios libros sobre Neruda (Neruda a través de sus metáforas, publicado en 1984; Neruda, el gran amigo, en 1986, y Los rostros de Neruda, en 1988). Así cumple con las condiciones de poder haber estado informado y captar el valor de aureomicina como material poético. Hemos conversado con el Dr. Velasco recientemente (julio 2009, entrevista personal) y nos ha señalado que es posible pero no seguro. En su infinita curiosidad Neruda lo interrogó muchas veces sobre muchos temas.

Hasta aquí hemos visto como Neruda usa como material poético el nombre comercial de un antibiótico de muy reciente introducción. Lo cual ya es curioso en sí mismo, pero lo realmente sorprendente viene en los versos sucesivos:

Según supe por lo que hablaban

el problema era como sigue:

nunca murió tanto microbio,

toneladas de ellos caían,

pero los pocos que quedaron

se manifestaban perversos.
La descripción del problema no puede ser más acertada. Desde la aparición de los antibióticos en la práctica clínica hemos vivido en el paradigma de que al aparecer un nuevo antibiótico aparece la resistencia de las bacterias y éste se hace inútil, pero ya aparece otro nuevo antibiótico que salva la situación. Nada han logrado los expertos que durante muchos años han señalado los riesgos del uso indiscriminado de estos medicamentos. Por ser tan útiles, y su efecto tan espectacular cuando están bien indicados, la tentación de usarlos indiscriminadamente ha sido irresistible por muchos años. Uno de los títulos de conferencia más frecuente por años ha sido: Uso y Abuso de Antibióticos y se escuchan frases tan ingeniosas como: «Deja que el antibiótico busque la infección». No cabe duda que nunca murió tanto microbio, toneladas de ellos han caído.

La consecuencia ha sido la perversión de los gérmenes. Muy poco después de que los antibióticos fueron introducidos como parte del arsenal terapéutico de la medicina se observó un curioso fenómeno. En un tiempo variable después de comenzar el uso de una de estas sustancias las bacterias que antes morían se hacen resistentes al efecto antibiótico. Los mecanismos por los cuales las bacterias logran hacerse resistentes a los antibióticos son de lo más ingeniosas que uno pudiera imaginar. Van desde el desarrollo de enzimas capaces de degradar la sustancia, modificaciones genéticas para modificar los sitios en que el antibiótico necesita unirse para penetrar la bacteria o engrosar su pared como quien adquiere una coraza. Más aún, en algunas ocasiones estos mecanismos se traspasan de bacterias de una especie a las de otra. Con algo de razón el asunto ha sido visto por algunos como una batalla en que nosotros desarrollamos nuevas armas y nuestro enemigo nuevas defensas ante éstas, una batalla que lleva 70 años y en la que parece llevamos las de perder. No cabe duda entonces: nunca murió tanto microbio, / toneladas de ellos caían, I pero los pocos que quedaron / se manifestaban perversos.

Es difícil especular acerca de cómo Neruda llegó a entender el fenómeno de la resistencia a los antibióticos. Posiblemente recibió información de parte de algún experto, pero esta vez puedo estar seguro de que no fue el Dr. Velasco, su amigo infectólogo. En 1986, conversé con él y me hizo un comentario que recuerdo hasta hoy y que descarta que haya valorado la importancia de la resistencia 
a los antibióticos. Dijo en ese entonces, que los infectólogos habían hecho tan bien su trabajo que se habían quedado sin trabajo. Me ha repetido recientemente su afirmación, echando por tierra mi ilusión de que se tratara de una metáfora que había que descifrar. Nada más equivocado que la apreciación de nuestro querido Dr. Velasco: con el tiempo, y en gran medida debido a la resistencia de los gérmenes a los antibióticos, la infectología ha aumentado su importancia en la medicina llegando a ser una especialidad muy preciada y con mucho trabajo.

\section{Me dejaron tan asustado que busqué a los enterradores. \\ Me fui a los ríos donde queman \\ grandes cadáveres pintados, \\ pequeños muertos huesudos, \\ emperadores recubiertos \\ por escamas aterradoras}

¿De qué pudo asustarse tanto el poeta? Al momento de escribir los versos se conocía la capacidad de los gérmenes de desarrollar resistencia, pero ni remotamente se visualizaba la importancia que llegaría a tener, la que de verdad produce susto.

La primera referencia en Chile a este fenómeno como un problema lo encontramos en una conferencia del Dr. Leonardo Paredes titulada "El Problema de la Resistencia de los Gérmenes a los Antibióticos", que obtuvo un premio de la Sociedad Médica de Santiago en 1957 (en C. Larraín, Historia de la Sociedad Médica de Santiago). Sin embargo, sólo emergió como un problema de cierta importancia clínica a principios de los setenta con la aparición de resistencia a las penicilinas semisintéticas. Con el tiempo ha llegado ha ser una dramática realidad de la medicina actual.

Un reciente artículo de la prestigiosa revista New England Journal of Medicine comenta el «super desafío» que representa la resistencia de los gérmenes a los antibióticos para la medicina del siglo XXI. Para ilustrar la situación comienza describiendo dos casos que me permito resumir.

El primero data de 1942: en un hospital en New Haven una mujer de 33 años estaba muriendo a causa de una septicemia por estreptococo. A pesar de todos los esfuerzos de los médicos, que habían aplicado todos los conocimientos de la ciencia médica, no habían podido erradicar al germen de su sangre. Entonces consiguieron pequeñas canti- dades de una sustancia recientemente descubierta llamada penicilina, la que inyectaron cuidadosamente a la paciente. Después de varias dosis la paciente se recuperó completamente y vivió hasta los noventa años. El segundo data de 2008 y describe el caso de un hombre de 77 años afectado de una endocarditis infecciosa (infección de la capa más interna del corazón) por Enterococcus faecium resistente a la vancomicina (el antibiótico indicado en este tipo de infecciones). A pesar de la administración por muchos días de los mejores antibióticos, fue imposible erradicar el germen resistente a todos ellos y el paciente falleció con el germen circulando en su sangre.

Los dos ejemplos muestran como después de 66 años hemos recorrido un camino circular que nos ha dejado en el punto de partida: la era previa a los antibióticos. Más aún, en los últimos años la investigación de nuevas sustancias antibióticas por parte de la industria farmacéutica ha decaído enormemente, poniéndonos en riesgo de quedar sin armas efectivas contra el enemigo.

Otra mirada posible es desde la salud pública, donde el problema es igualmente alarmante y se puede ilustrar con la situación de una vieja amiga de la humanidad, la tuberculosis. A pesar de haberse estabilizado su frecuencia en los últimos años, la tuberculosis sigue afectando a 10 millones de individuos en el mundo cada año, el $80 \%$ de los cuales en países pobres, de los cuales 500.000 son causados por gérmenes resistentes a múltiples antibióticos. Se estima que el plan global para detener la tuberculosis requerirá entre el 2009 y el 2015 tratar 1.400 .000 casos de tuberculosis causada por este tipo de gérmenes, con un costo de 16,9 mil millones de dólares, 61 veces lo disponible actualmente para este plan.

Estos versos son un buen ejemplo del oficio de Neruda, un poeta íntimamente ligado a la naturaleza, un científico de alto nivel, poseedor de infinita curiosidad y dotado de la intuición propia de los grandes maestros. Hemos buscado sin éxito sus fuentes de información. Para entender como llegó a conocer, entender profundamente y proyectar de forma tan acertada el asunto, sólo podemos recurrir a la segunda acepción de Vate: adivino.

Agradecimientos: Al Profesor Hernán Loyola por la revisión del manuscrito, su consejo permanente y su generosa amistad. 